\title{
Experimental and Numerical Investigation of Shock Wave Propagation Due to Dam-Break Over a Wet Channel
}

\author{
Evren Turhan ${ }^{1 *}$, Hatice Ozmen-Cagatay ${ }^{2}$, Selahattin Kocaman ${ }^{3}$ \\ ${ }^{1}$ Department of Civil Engineering, Adana Science and Technology University, Adana, Turkey \\ ${ }^{2}$ Department of Civil Engineering, Cukurova University, Adana, Turkey \\ ${ }^{3}$ Department of Civil Engineering, Iskenderun Technical University, Hatay, Turkey
}

Received: 19 February 2018

Accepted: 3 July 2018

\begin{abstract}
We investigated the propagation of shock waves in a prismatic rectangular channel with a horizontal wet bed. Saltwater was used as a Newtonian fluid within the entire channel instead of normal water for representing the different density fluids. It aims to point out seawater where tsunamis occur as an extreme example of shock waves. The shock waves were generated by sudden lifting of a vertical gate that separated a reservoir and a downstream channel with three different tailwater depths. The experimental data were digitized using image processing techniques. Furthermore, the flow was numerically solved by using Reynolds Averaged Navier-Stokes (RANS) equations and a DualSPHysics program (a code version of smoothed particle hydrodynamics (SPH)). After sudden removal of the vertical gate the propagations of shock waves were experimentally examined via image processing, which can yield both free surface profiles at several times and variations of flow depth with time at four specified locations. Solution successes of two different numerical methods for this rapidly varied unsteady flow are tested by comparing the laboratory data. The results indicate that the disagreements on graphs of time evolutions of water levels obtained from two numerical simulations decrease when the initial tailwater levels increase.
\end{abstract}

Keywords: shock wave, RANS, DualSPHysics, saltwater, image processing

\section{Introduction}

Shock wave propagation induced by a dam break over an initially wet channel is an interesting topic in fluid dynamics since it is the most chaotic problem in rapidly varied unsteady flows. It is very important to

*e-mail: eturhan@adanabtu.edu.tr understand the behavior of the flow in order to estimate flood size and manage the flood hazards by taking urgent precautions. Analytical solutions of such flows can be possible under certain assumptions. Hence numerical methods are required for exact solution. Recently, with the rapid development in computing capacity, numerical simulations have become more popular. However, the accuracy of numerical simulations should be validated with laboratory data due to the absence of field data. 
Unfortunately, as compared to many numerical works, few laboratory works are available in the literature.

Stoker [1] obtained a water surface profile of dambreak flow in a frictionless prismatic channel with horizontal wet bed and infinite length. Bellos et al. [2] performed several experiments in horizontal, smooth, dry, and wet channels with converging-diverging geometries, and then compared the experimental data with the numerical solution results. Mohapatra and Bhallamudi [3] investigated numerically the effects of the contractions and expansions on the dam-break flow depth at the dam site. Lauber and Hager [4] conducted a lot of experiments about the dam-break flow problem and proposed that dam breaks can be accepted as a sudden break when the lifting time of the gate is less than $1.25(\mathrm{~h} / \mathrm{g})^{1 / 2}$. Flow depth, average velocity in cross sections, and positive and negative wave front velocities were the main measured physical characteristics. They compared the experimental results with the analytical solutions which were available in the literature. Stansby et al. [5] experimentally studied the propagation of flood shock waves that occurred as a result of sudden lifting of a vertical gate separating a reservoir and a smooth, horizontal downstream channel. Bukreev et al. [6] conducted experiments about dam-break flow for dry and wet downstream and they compared the measured results with the numerical solution results of shallow water equations (SWE). Janosi et al. [7] investigated turbulence effects in the case of a dam break. Both water and polyethylene-oxide (PEO) solution as fluids were used in their experiments. When PEO solution was used, they noted that reducing turbulence effect had a positive effect in dry channel, but only slight effect in wet bed. Chanson et al. [8] studied the dam-break wave of thixotropic fluid and the results showed that the thixotropic nature of the fluid has a strong influence on flow motion. Kocaman [9] extensively investigated the dam-break flow problem experimentally. Kocaman and Ozmen-Cagatay [10] experimentally examined how dam-break-induced shock waves impact a vertical wall over wet bed with two different tailwater levels in a closed downstream channel. Evangelista et al. [11] conducted an experimental study of erosion of a sand dike produced by the impact of a sudden dam-break wave. Aureli et al. [12] experimentally investigated the impact of dam-break wave on a structure. Di Cristo et al. [13] performed a few experiments of dam-break wave over an erodible embankment.

Gomez-Gesteira and Dalrymple [14] tried to simulate shock wave propagation resulting from dam-break in wet channel with SPH method, and numerical results show good agreement with experiments. Dalrymple and Rogers [15] examined shock wave propagation using the SPH method by focusing the parameters of turbulence, viscosity, and density, and tried to solve wave-structure interaction problems. Crespo [16] performed experiments on dam-break flow and wave-structure interaction and then compared the results with two and threedimensional SPH results. He emphasized that SPH could be a useful method in terms of solutions of different wave problems. Shakibaeinia and Jin [17] developed a mesh-free particle model for simulation of mobile-bed dam-break and concluded that the SPH method could easily be used in computational fluid dynamics (CFD) problems by validating the model with the experimental data in the literature. $\mathrm{Xu}$ [18] numerically examined wave propagation resulting from dam-break by using the three-dimensional SPH method and reported that SPH would be a useful numerical method to estimate the characteristics of such a flow. Jian et al. [19] simulated dam-break flows around movable structures by SPH method. Turhan [20] experimentally and numerically investigated dam-break flow for different density fluids such as water, oil, and saltwater within the channel. Zhang et al. [21] simulated dam-break flow with a threedimensional implicit unstructured-mesh finite element model by using Flow-3D software, which is based on RANS and shallow water approaches. Kocaman and Ozmen-Cagatay [22] simulated with RANS the effect of lateral channel contradiction on dam-break shock wave propagation downstream. Cubos-Ramirez et al. [23] developed a three-dimensional numerical model by solving Navier-Stokes equations for non-compressible fluids using the volume of fluid (VOF) method for free surface modeling. Evangelista et al. [24] simulated different real dam-break scenarios, not only under fixedbed but also under mobile-bed conditions by applying the first-order numerical scheme GMUSTA. Song et al. [25] developed an unstructured, Godunov-type finitevolume model in order to simulate two-dimensional dam-break floods over complex topography with wetting and drying.

In this study, the propagation of a dam-breakinduced shock wave was investigated in a rectangular channel with horizontal wet bed for three different tailwater depths. A new experimental study was carried out by using salt water within the entire channel as a Newtonian fluid instead of normal water. In the laboratory tests, the digital image processing technique was adopted for flow measurement. Since the channel downstream was closed with a gate, reflection of the shock wave against the wall was also investigated as tsunami wave propagation. Regarding the research in the field, using salt water as a Newtonian fluid in rapidly varied unsteady flow is a novelty of this paper. The use of a small-scaled laboratory model shows a more chaotic case in the dam-break flow due to early reflection from the end gate of the downstream channel. In this content, experimental studies are challenging as well as valuable. Furthermore, in this paper, numerical simulation of the flow was performed by applying two different approaches: RANS equations and particlebased smoothed particle hydrodynamics (SPH). The numerical results were compared with the experimental data in terms of flow characteristics, thus verifications of the numerical methods were tested. The present study mainly focuses on the effects of tailwater level on shockwave propagation by obtaining the snapshots 


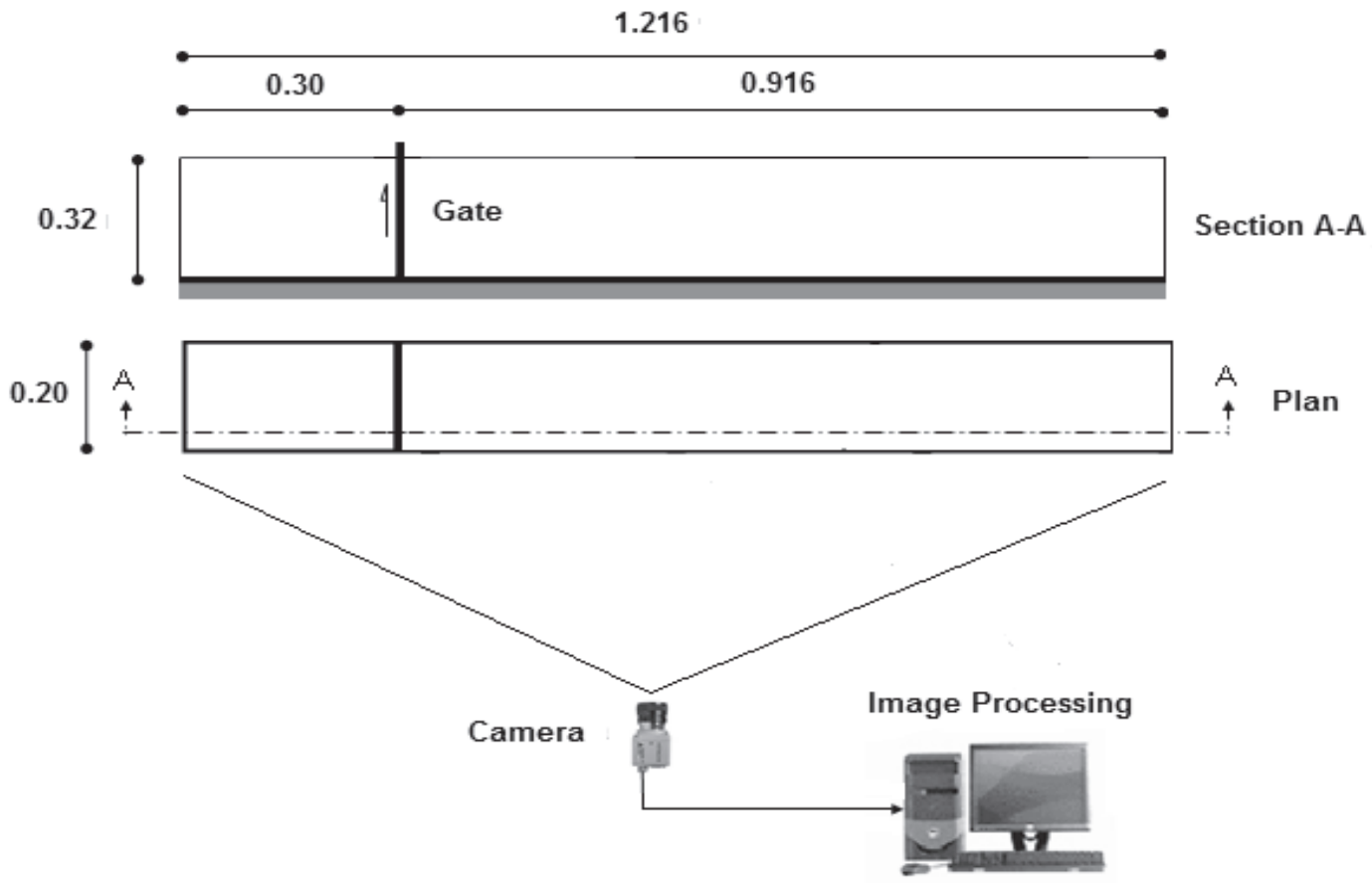

Fig. 1. Experimental setup: (a) section A-A, (b) plan, lengths in (m).

of the free surface profiles at several times and level changes with time at certain positions.

\section{Material and Methods}

\section{Experimental Set-Up}

The new experiments were carried out at the Mechanical Engineering Laboratory of Adana Science and Technology University in a horizontal and rectangular channel $1.216 \mathrm{~m}$ long, $0.20 \mathrm{~m}$ wide, and $0.32 \mathrm{~m}$ high [20]. The channel bottom and walls were made of $5 \mathrm{~mm}$ thick plexiglass. A gate made of $3 \mathrm{~mm}$ plexiglass which separated the reservoir and downstream channel was located $0.30 \mathrm{~m}$ from the channel entrance. The mortise where the gate would be placed, made from the plexiglass $(1 \mathrm{~cm}$ long and $3 \mathrm{~mm}$ thick) as four pieces. These pieces were mounted to the channel using chloroform adhesive. The geometry and dimensions of the channel sections are shown in Fig. 1.

A metal component with $2 \mathrm{~kg}$ weight was attached by aid of the screws on the top of the gate in order to provide a rigid connection between the gate and the pulley system. Since this metal provided a weight, it also helped to prevent leakage from the reservoir to the downstream channel. The metal part connected to the rope was drawn over a pulley following the fall a 12-kg sack. Vaseline was plastered between the contact edges of the gate and the channel walls to prevent leakage. Three plexiglass clamps were installed at certain intervals of the channel top to prevent the possible deformation of the channel. The test area was lit by constant light sources. A white styrofoam plate was placed behind the channel to prevent reflection of any object around the channel. Components of the experimental set-up and the gate mechanism are shown in Fig. 2. At the beginning of the experiments, the reservoir was filled with salt water up to height of $\mathrm{h}_{\mathrm{o}}=0.15 \mathrm{~m}$ and the gate was removed at a duration of less than $1.25(\mathrm{~h} / \mathrm{g})^{1 / 2}[4]$. Therefore, unsteady flow conditions were provided.

By releasing the weight from a certain height, the gate was suddenly lifted [9]. In the experiments, the upper limit of the sudden removal time was determined as $\mathrm{t}=0.155 \mathrm{~s}$ for $\mathrm{h}_{\mathrm{o}}=0.15 \mathrm{~m}$ [4]. The lifting time from gathered video images is less than about $0.10 \mathrm{~s}$, thus sudden break conditions were provided. Three experiments were conducted for different depth ratios such as $\alpha=0.10,0.20$, and 0.40 . The depth ratio is expressed as $\alpha=h_{t} / h_{0}$, where $h_{0}$ and $h_{t}$ are initial reservoir depth and tailwater depth, respectively. Prior to each test, the reservoir was initially filled with salt water up to height of $h_{0}=0.15 \mathrm{~m}$. The initial salt water

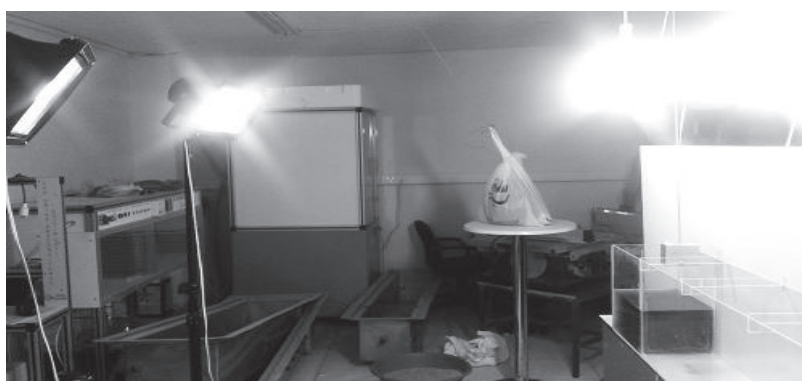

Fig. 2. Components of the experimental set-up and gate mechanism. 


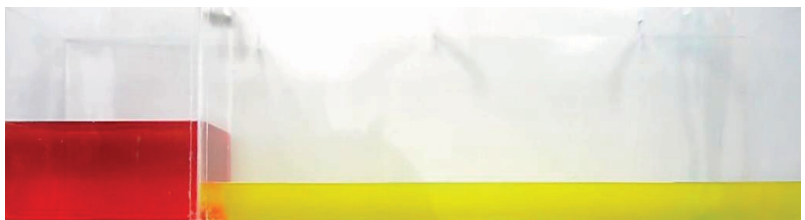

Fig. 3. Experimental snapshot at $\mathrm{t}=0$ for $\alpha=0.40$.

in the reservoir and tailwater in the downstream were colored with different artificial food coloring in order to describe the behavior of the flow (Fig. 3). The most important advantage of food coloring is that it can be homogeneously dispersed and does not adversely affect flow propagation. Particularly, different colored food stains have been added to fluid in the downstream with the aim of observing flow behavior easily.

The density of salt water was set as $1200 \mathrm{~kg} / \mathrm{m}^{3}$. The mixing ratio of salt water was evaluated as $20 \%$. After adding salt to a pail with water, the heterogen mixture was blended homogenously using a lathe machine. Afterward, the obtained fluid mixture was evaluated by simple density measurement method to find the density value. Its viscosity was measured as $0.018 \mathrm{~kg} / \mathrm{m}$.s via a viscometer at $23.7^{\circ} \mathrm{C}$ [20].

\section{Flow Measurement and Calibration}

As seen in Fig. 4, the calibration process was applied by matching corner coordinates in different views of the calibration board. Thus, the distortions were calibrated using Matlab [26]. Images were obtained using a camera with high resolution and speed without changing positions. Video images were digitized as $1280 \times 720$ pixels at 60 frames per second. Subsequently, the pixel values of images were converted into the lengths. Red stripes were stuck on the side walls and bottom of the channel with the aim of determining the measurements. Required filtering was performed during image processing. Sharpness was adjusted by crosssectional contrasts, which are the changes of color levels of the images. Thus, the colors are enhanced and the calibration error rate could be realized at minimal levels. Salt water level changes over time at specified sections

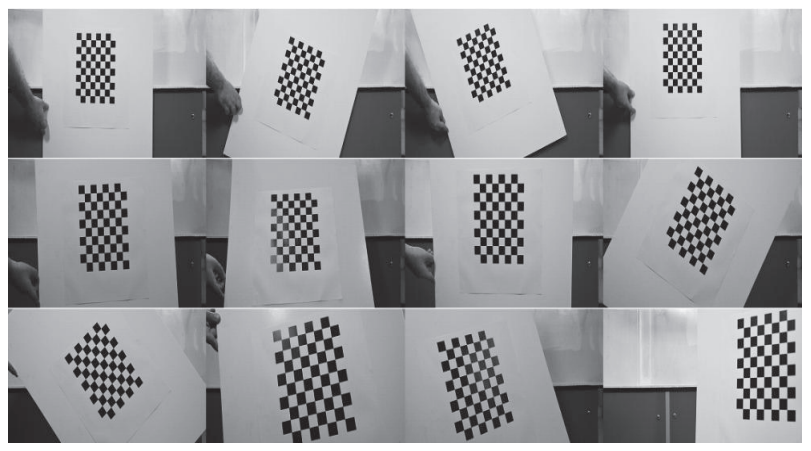

Fig. 4. Calibration board. were determined from digital images of experiments using virtual wave probes. The virtual wave probe is used to evaluate the sudden changes between colors of neighboring pixels on the images (i.e., gray tone values) as an edge with the help of a drawn arrow $[9,10]$.

Fig. 5 shows four measurement positions: the first one (P1) is in the middle of the reservoir and the others (P2, P3, P4) in chosen sections along the downstream. Salt water level variations over time were obtained at these positions. Dimensionless magnitudes have been taken into account in graphs. $\mathrm{h}, \mathrm{h}_{\mathrm{o}}, \mathrm{g}$, and t represent channel height, initial reservoir level, acceleration of gravity, and time, respectively. Depth level changes over time were measured by image processing and H-T graphics were obtained. $\mathrm{H}$ and $\mathrm{T}$ are dimensionless parameters and they are expressed as $\mathrm{H}=\mathrm{h} / \mathrm{h}_{\mathrm{o}}$ and $\mathrm{T}=\mathrm{t}\left(\mathrm{g} / \mathrm{h}_{\mathrm{o}}\right)^{1 / 2}$.

\section{Numerical Simulations}

\section{Reynolds Averaged Navier-Stokes (RANS) Equations}

RANS equations (continuity and momentum) for incompressible Newtonian fluid flow are seen in Eqs. (1) and (2) [9]:

$$
\begin{gathered}
\frac{\partial \mathrm{u}_{\mathrm{i}}}{\partial \mathrm{x}}=0 \\
\rho \frac{\partial \mathrm{u}_{\mathrm{i}}}{\partial \mathrm{t}}+\rho \frac{\partial\left(\mathrm{u}_{\mathrm{i}} \mathrm{u}_{\mathrm{j}}\right)}{\partial \mathrm{x}_{\mathrm{j}}}=-\frac{\partial \mathrm{p}}{\partial \mathrm{x}_{\mathrm{i}}}+\mu \frac{\partial}{\partial \mathrm{x}_{\mathrm{j}}}\left(\frac{\partial \mathrm{u}_{\mathrm{i}}}{\partial \mathrm{x}_{\mathrm{j}}}+\frac{\partial \mathrm{u}_{\mathrm{j}}}{\partial \mathrm{x}_{\mathrm{i}}}\right) \\
-\rho \frac{\partial\left(\overline{\mathrm{u}_{\mathrm{i}}{ }^{\prime} \mathrm{u}_{\mathrm{j}}{ }^{\prime}}\right)}{\partial \mathrm{x}}+\rho \mathrm{g}_{\mathrm{i}}
\end{gathered}
$$

...where $\rho$ is density, $u_{i}$ and $u_{j}$ denote velocity component in the specified direction, $t$ is time, $\mathrm{p}$ is pressure, $\mu$ is dynamic viscosity, and $\mathrm{g}_{\mathrm{i}}$ is body acceleration in the specified direction.

When comparing this equation with Navier-Stokes, it can be seen that there is an additional term, $\partial\left(\rho \overline{u_{i}{ }^{\prime} u_{j}{ }^{\prime}}\right) / \partial x_{j}$, that describes turbulence-induced or Reynolds stresses. In RANS equations, scalar values of all physical properties of the flow are evaluated as average values. The number of equations is the same with the unknown number in the laminar flow. However, in RANS equations different terms have to be added to existing equations. Hence, turbulence closure models are required to solve these problems. It is necessary to accurately estimate the value of turbulence viscosity $\mu_{t}$, which is used in the solution of the time varying RANS equations. Various turbulence models have been used in the literature such as renormalization group (RNG), $\mathrm{k}-\omega$, k- $\varepsilon$ etc. [27]. Among them, the k- $\varepsilon$ turbulence model is the most commonly preferred one for the closure process [9-28-29].

In this study, the numerical solutions of RANS were computed by CFD package software of the flow-3D 


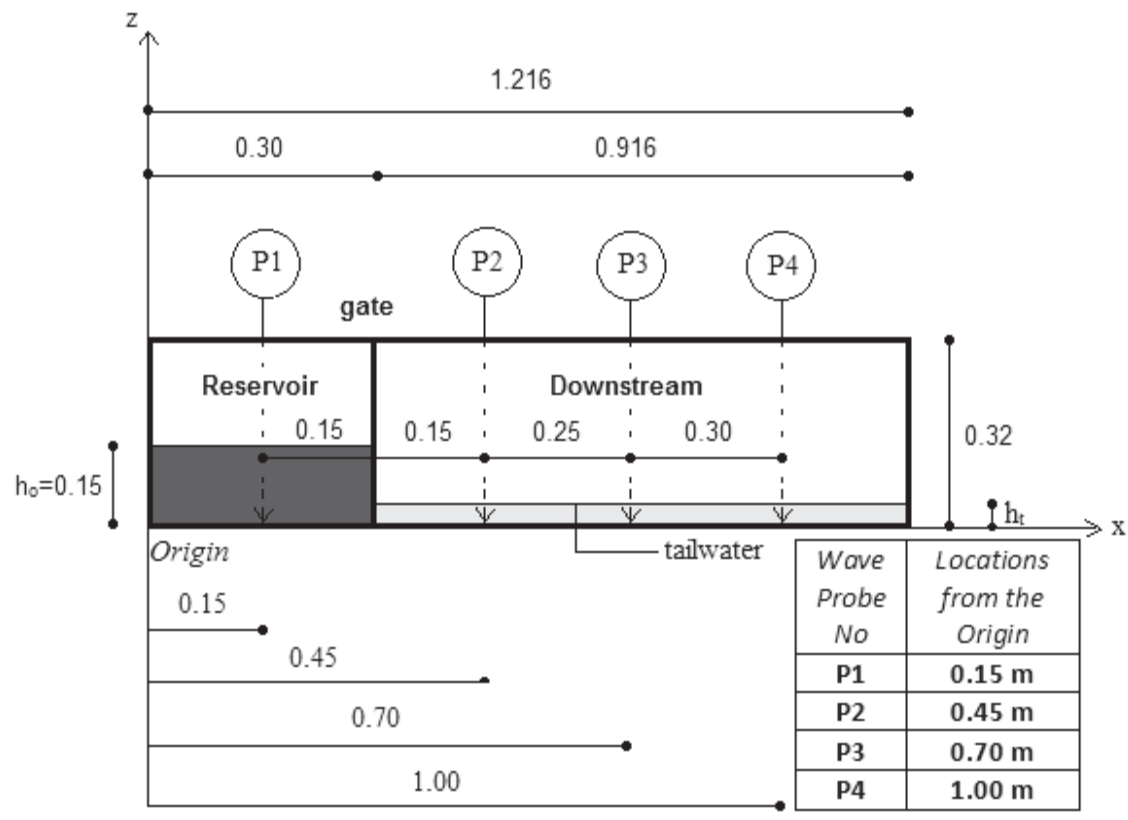

Fig. 5. Measurement positions (lengths in $\mathrm{m}$ ).

contained VOF method [30]. This program is based on the mesh-grid system. It uses a cell porosity technique, i.e., fractional area/volume obstacle representation method (FAVOR). All the surfaces of the channel bottom and sidewalls were assumed to be smooth. The channel sidewalls were chosen as symmetry, implying no flux and shear of any property across it. Tangential and normal velocities were zero at the solid boundary due to defining the no-slip condition [10]. In this paper, a grid size was adopted as $5 \mathrm{~mm}$ after performing sensitivity analysis for $2 \mathrm{~mm}$ and $10 \mathrm{~mm}$. The time step $\Delta \mathrm{t}$ was determined according to the Courant-Friedrichs-Lewy (CFL) criterion. Flow-3D automatically determined $\Delta \mathrm{t}$.

\section{Smoothed Particle Hydrodynamics (SPH) Method}

SPH is defined as a method involving numerical solutions of the fluid dynamics equations represented as a set of particles and also involving the displacement of fluid [15]. The most important features of this method are particle tracking and the mesh-free Lagrangian method. Navier-Stokes equations, which are discretized in fluid dynamics problems, can be integrated according to physical properties of the particles surrounding the position of each particle (i.e., "r") W: Kernel function and h: smoothing length [31].

Average smoothing is calculated as Eq. (3):

$$
F(r)=\int F\left(r^{\prime}\right) W\left(r-r^{\prime}, h\right)\left(d r^{\prime}\right)
$$

"W" applied in the smoothing process can contain some different features. It is possible to count a few of these properties as being positive in defined interaction region and fully contributing, monotonically decreasing resulting values due to normalization and distance. The function is applied to particle "a" over a set of particles. Also, this function is considered in dependent regions defined by "h." Therefore, a summation is performed for all the particles within these regions of support of the kernel (Eq. 4) [32]:

$$
\mathrm{F}\left(\mathrm{r}_{\mathrm{a}}\right) \approx \sum_{\mathrm{b}} \mathrm{F}\left(\mathrm{r}_{\mathrm{b}}\right) \mathrm{W}\left(\mathrm{r}_{\mathrm{a}}-\mathrm{r}_{\mathrm{b}}, \mathrm{h}\right) \Delta \mathrm{v}_{\mathrm{b}}
$$

In this equation, "a" and "b" represent individual particles. Additionally, $\Delta \mathrm{v}_{\mathrm{b}}$ denotes the volume of neighboring particle "b." If volume is expressed by $\Delta \mathrm{v}_{\mathrm{b}}=\mathrm{m}_{\mathrm{b}} / \rho_{\mathrm{b}}, \mathrm{m}$ is the mass and $\rho$ is the density of particle "b." Eq. (4) can be written in the following equation (Eq. 5) [16]:

$$
\mathrm{F}\left(\mathrm{r}_{\mathrm{a}}\right) \approx \sum_{\mathrm{b}} \mathrm{F}\left(\mathrm{r}_{\mathrm{b}}\right) \frac{\mathrm{m}_{\mathrm{b}}}{\rho_{\mathrm{b}}} \mathrm{W}\left(\mathrm{r}_{\mathrm{a}}-\mathrm{r}_{\mathrm{b}}, \mathrm{h}\right) \Delta \mathrm{v}_{\mathrm{b}}
$$

The momentum equation is used to determine the acceleration of particle "a" as a result of interaction of neighboring particle " $b$ " (Eq. 6) [33]:

$\frac{d V_{a}}{d t}=-\sum_{b} m_{b}\left(\frac{P_{b}}{\rho_{b}{ }^{2}}+\frac{P_{a}}{\rho_{a}{ }^{2}}+\prod a b\right) \nabla_{a} W_{a b}+g$

...where $\mathrm{v}$ is velocity, $\mathrm{P}$ is pressure, $\mathrm{m}$ is mass, and $\mathrm{W}_{\mathrm{ab}}$ is kernel function. $\mathrm{W}_{\mathrm{ab}}$ depends on the distance between particles " $a$ " and " $b$," and $\Pi_{a b}$ denotes artificial viscosity term [34]. In this paper cubic spline was selected as 
the kernel function type as seen in Eq. 7, since it was the most frequently used one in the literature [35-36].

$$
W(r, h)=\alpha_{D}\left\{\begin{array}{cr}
1-\frac{3}{2} q^{2}+\frac{3}{4} q^{3} & 0 \leq q \leq 1 \\
\frac{1}{4}(2-q)^{3} & 1<q \leq 2 \\
0 & q>2
\end{array}\right.
$$

The mass for each particle is constant and differences in fluid densities are calculated by solving the conservation of mass or continuity equation (Eq. 8) [37]. Pressure is computed using Tait's state equation [38] (Eq. 9):

$$
\begin{aligned}
\frac{\mathrm{d} \rho_{\mathrm{a}}}{\mathrm{dt}} & =\sum_{\mathrm{b}} \mathrm{m}_{\mathrm{b}} \mathrm{v}_{\mathrm{ab} .} \Delta_{\mathrm{a}} \mathrm{W}_{\mathrm{ab}} \\
\mathrm{P} & =\mathrm{b}\left[\left(\frac{\rho}{\rho_{0}}\right)^{\gamma}-1\right]
\end{aligned}
$$

...where $\gamma=7, \quad \mathrm{~b}=\mathrm{c}_{0}{ }^{2} \rho / \gamma, \rho_{0}$, reference density $\left(=1000 \mathrm{~kg} / \mathrm{m}^{3}\right), \mathrm{c}_{0}$ speed of sound at the reference density. Thus, Eq. (10) can be written as follows [39]:

$$
c_{0}=c\left(\rho_{0}\right)=\left.\sqrt{\left(\frac{\partial P}{\partial \rho}\right)}\right|_{\rho_{0}}
$$

In this study we used the Verlet algorithm for time stepping. A variable time-step that depends on CFL condition, forcing terms and viscous diffusion term are applied [40]. The CFL number was entered as 0.20 . Furthermore, boundary condition is practical to implement because of computational simplicity where the fluid-boundary interactions can be computed inside similar loops as fluid particles. Distance between particles (dp) was taken as 0.001 and it was not tried smaller than 0.001 in order to avoid computational load [41]. Several artificial viscosity values were tried between $0.05-0.20$, and the optimum value was determined as 0.10 . There are a lot of studies using different artificial viscosity values in SPH simulations $[35,36,41]$. Also, smoothing length was defined as 1.0. The set of parameters for SPH are given in Table 1.

\section{Results and Discussion}

The propagation of the shock waves generated from sudden lifting of the vertical gate was investigated along the partial salt water filling the downstream for
Table 1. Set of SPH parameters.

\begin{tabular}{|c|c|}
\hline Process & Options \\
\hline Version & DualSPHysics v4.0 \\
\hline Dimension & Cubic Spline \\
\hline Kind of Kernel & Verlet \\
\hline Time stepping $(\Delta \mathrm{t})$ & 0.20 \\
\hline CFL number & Shepard filter \\
\hline Density filter & Artificial viscosity $(\alpha=0.10)$ \\
\hline Viscosity treatment & Tait equation \\
\hline Equation of state & Dynamic \\
\hline Boundary conditions $(B C)$ & 1.0 \\
\hline Smoothing length & 3.0 \\
\hline Simulation length & 0.001 \\
\hline dp & 46857 \\
\hline The number of fluid particles & \\
\hline
\end{tabular}

three different depth ratios as $0.10,0.20$, and 0.40 . Once the vertical gate was suddenly lifted, the fluid in the reservoir tried to drag the fluid within the downstream. Even if the tailwater resisted, the shock wave was broken and a jet was formed during the early initial stage. Thus, the flow was forced to move upward [5, $9,10,42]$. We observed a fact like jet after dam-break and turbulence occurred in early dam-break stages [5]. Therefore, the free surface of the wave front sharpens over time and wave breaking is delayed. Time evolutions of free surfaces were handled as two parts according to time intervals. The first indicates the formation of shock waves after gate lifting during the very early stages from $\mathrm{t}=0.0 \mathrm{~s}$ to $\mathrm{t}=0.2839 \mathrm{~s}$ (Fig. 6), and the second part from $\mathrm{t}=0.4509 \mathrm{~s}$ to $\mathrm{t}=2.9893 \mathrm{~s}$ indicates reflection of the shock waves against the channel end gate (Fig. 7).

As displayed in Fig. 6 at $\mathrm{t}=0.0833 \mathrm{~s}$, free surface profiles look parabolic in the experiment and like both numerical models. However, after $\mathrm{t}=0.1336 \mathrm{~s}$, free surfaces become convex and wave fronts are concave in both experiments and numerical models. Between $\mathrm{t}=0.0833 \mathrm{~s}$ and $\mathrm{t}=0.2839 \mathrm{~s}$, wave fronts in the experiment are more steep than those in numerical modeling. At $t=1.002 \mathrm{~s}$ in Fig. 7, the reflection of the shock wave against the end wall starts and it moves in upstream with high turbulence resulted from wave breaking. As time progresses, the reflected wave front speeds are lower in SPH modeling than those in the experiment and RANS. Herein, Flow-3D is more successful in the prediction of reflected wave behavior than SPH simulation. In general, Figs 6 and 7 show good agreement between measurements and numerical simulation results of RANS and SPH. Fig. 8 shows a comparison between measured and computed flow depth variations over time for $\alpha=0.10$ at four selected locations. 


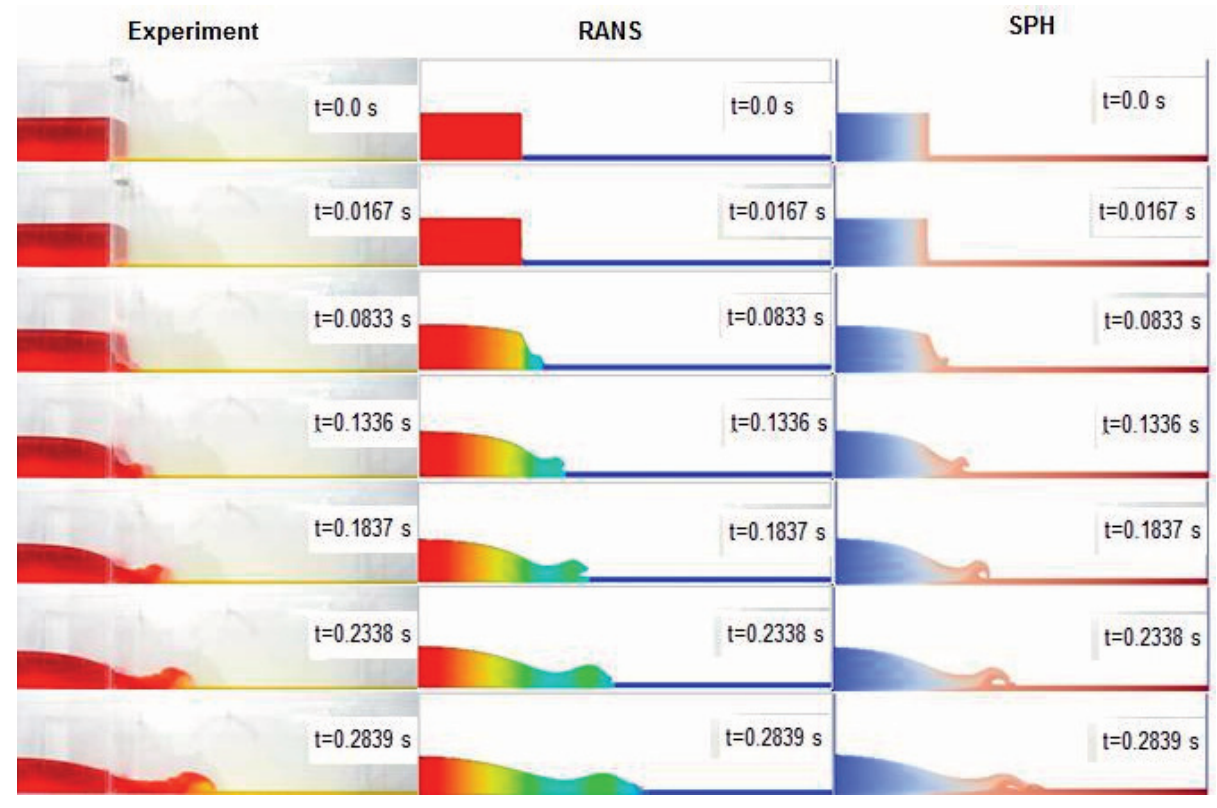

Fig. 6. Evolution of surface profiles with time at very early stages after gate lifting from $t=0.0$ to $t=0.2839 \mathrm{~s}$ for $\alpha=0.10$ (experiment, RANS, and SPH).

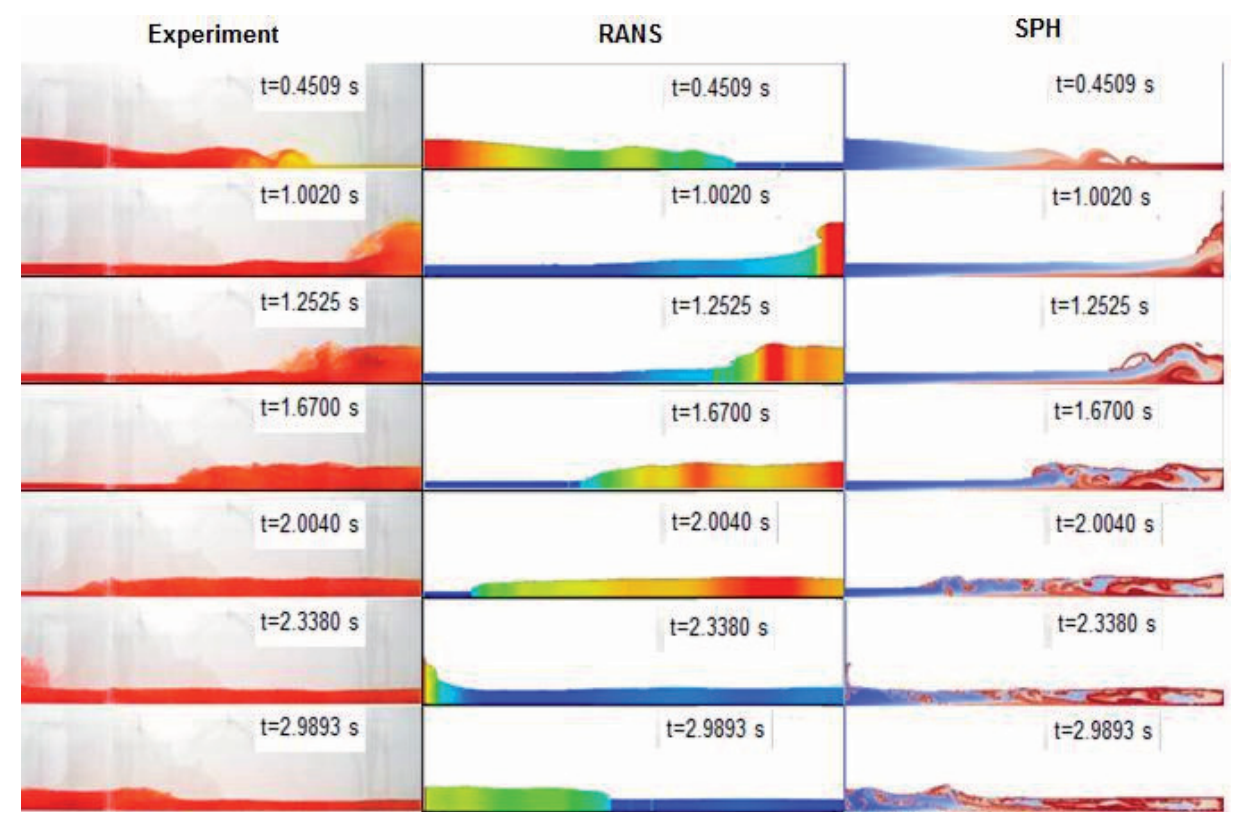

Fig. 7. Evolution of free surface profiles of reflected waves with time from $t=0.4509 \mathrm{~s}$ to $\mathrm{t}=2.9893 \mathrm{~s}$ for $\alpha=0.10$ (experiment, RANS, and $\mathrm{SPH})$.

In Fig. 8 at $\mathrm{P} 1=0.15 \mathrm{~m}$, RANS simulation shows very good agreement with experiment while $\mathrm{SPH}$ shows little discrepancy - especially at $\mathrm{T}=20-22$. At $\mathrm{P} 2=0.45 \mathrm{~m}$, numerical simulations underestimate the flow depths most of the time. Fig. 8 shows disagreements between the experimental data and both numerical solution results at $\mathrm{P} 3=0.70 \mathrm{~m}$. On the graph, the first jump was significantly delayed in the numerical simulations and the reflected wave front cannot be predicted well both in terms of arrival time and water level. SPH solution apparently overestimates the peak value of salt water level, which can result from the effect of splashing of any particles [42, 43]. Furthermore, both numerical simulations cannot predict flow level at the end of time. At the last location P4, the highest peak value $(H=0.8)$ occurs in RANS simulation. In contrast, in a similar previous study that compared the same graphs of H-T in the case of the fluid was water, RANS solution showed good agreement with the experimental data for $\alpha=0.10$ [44]. Figs 9 and 10 show evolutions of the free surface profiles with time for $\alpha=0.20$. 

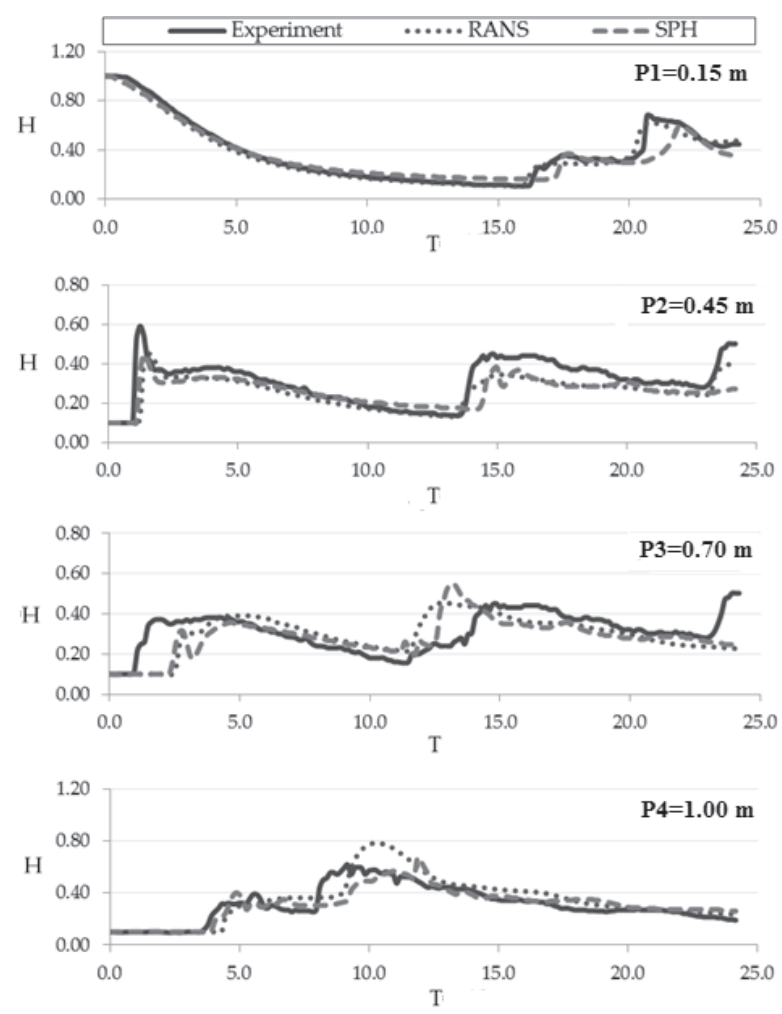

Fig. 8. Experimental and numerical comparison of flow depth variations with time for $\alpha=0.10$ (P1, P2, P3, and P4).

Fig. 9 denotes the snapshots of the flow behavior at the very early stage $t=0.0-0.2839$ s. Once the gate was lifted, the initial reservoir salt water dragged the tailwater. The still tailwater for $\alpha=0.20$ has a higher pressure force than that for $\alpha=0.10$. It resists the dragging force of the salt water in the reservoir, which forces it to move in a vertical direction. Therefore, the wave crest sharpens $(\mathrm{t}=0.1837-0.2839 \mathrm{~s})$ and the full wave breaking is obviously not seen in Fig. 9. The speed of the wave front is slower for $\alpha=0.20$ than that for $\alpha=0.10$. The shock wave breaks early and kinetic energy of the wave is high in shallow water in the case of $\alpha=0.10$. Thus turbulence intensity and air entrainment are high in the case of $\alpha=0.10$ compared to the case of $\alpha=0.20$ (Fig. 9). As displayed in Fig. 10, once the shock wave reflects against to the end wall at $1.2525 \mathrm{~s}$, the reflected wave starts to move in the upstream direction with decreasing wave front speed due to wall effect.

As a result, salt water level rises when the reflected wave (negative wave) collides with the moving shock wave in the opposite direction and the reflected wave front sharpens. Herein, the turbulence is formed and kinetic energy of the flow dissipates. There is good agreement between the experiment and RANS solution, while SPH solution shows little discrepancies (Fig. 10).

Fig. 11 shows the comparison of the experimental and numerical results of dimensionless time versus water depth at four locations for $\alpha=0.20$. At $\mathrm{P} 1=0.15 \mathrm{~m}$, the salt water level falls from dimensionless value $H=1.0$ to $H=0.2$, and after $T=15$ it rises to $\mathrm{H}=0.85$ with two successive jumps resulting from the impact of colliding shock wave to the moving reflected wave in the upstream direction. While both numerical solutions agree with the experimental data up to $\mathrm{T}=15$, they underestimate the peak water level around $\mathrm{T}=20$. This can result from a jet and turbulence entrance due to the impact of the shock wave to the wall. From P2 to P4, numerical solutions slightly underestimate the speed of negative wave front unlike in the previous work [10].

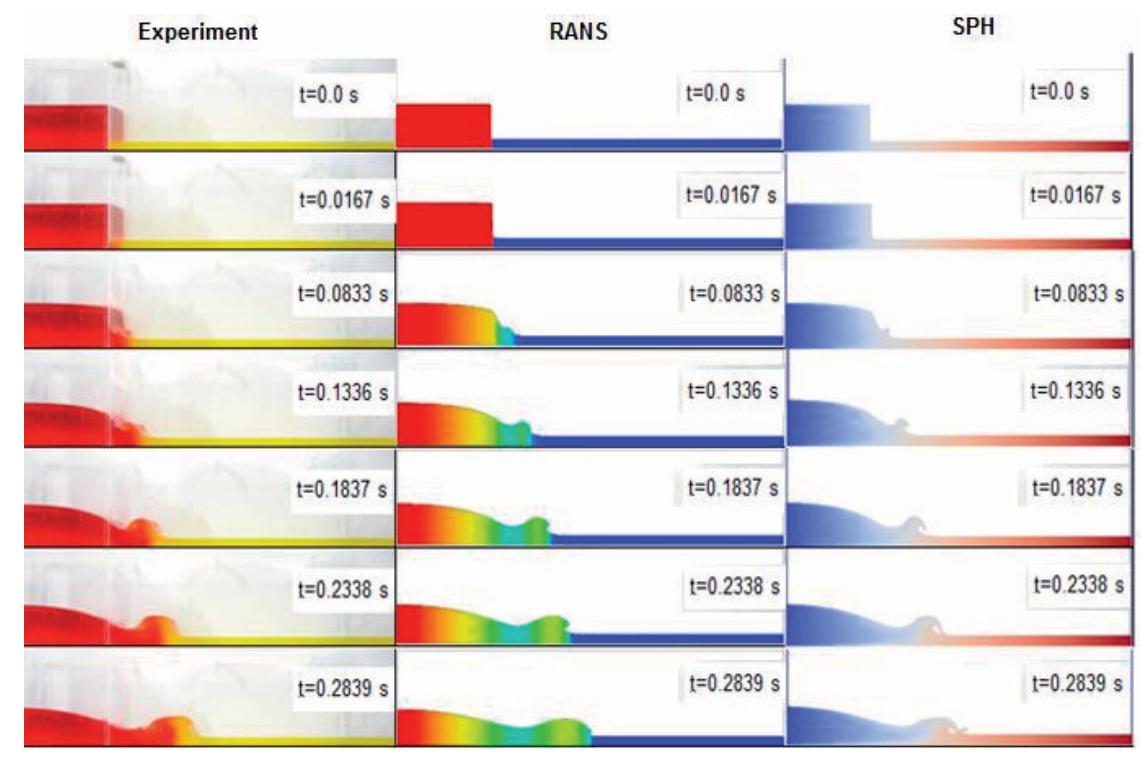

Fig. 9. Evolution of surface profiles with time at very early stages after gate lifting from $t=0.0$ to $t=0.2839 \mathrm{~s}$ for $\alpha=0.20$ (experiment, RANS, and SPH). 


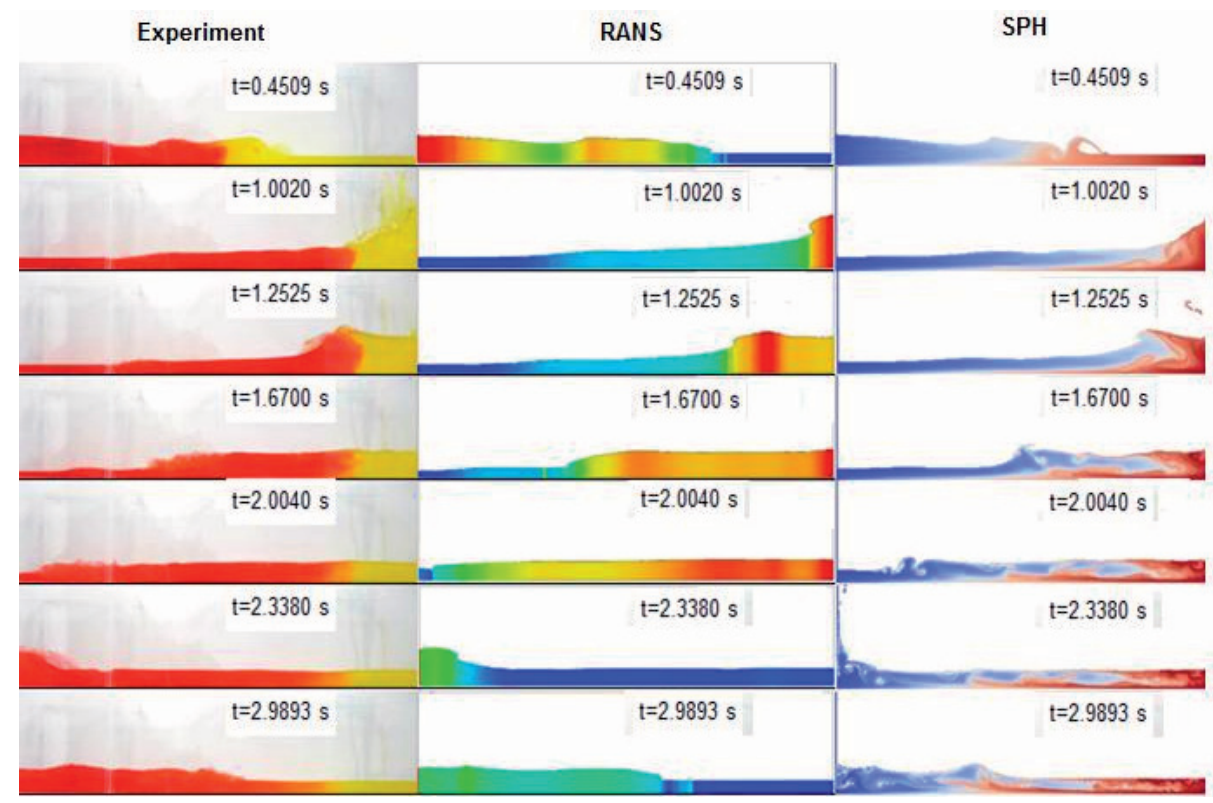

Fig. 10. Evolution of free surface profiles of reflected waves with time from $t=0.4509 \mathrm{~s}$ to $\mathrm{t}=2.9893 \mathrm{~s}$ for $\alpha=0.20$ (experiment, RANS, and $\mathrm{SPH})$.

The RANS simulation produces more reasonable results than SPH simulation for all locations. The findings show that the agreement between the experimental data and numerical solutions is better in
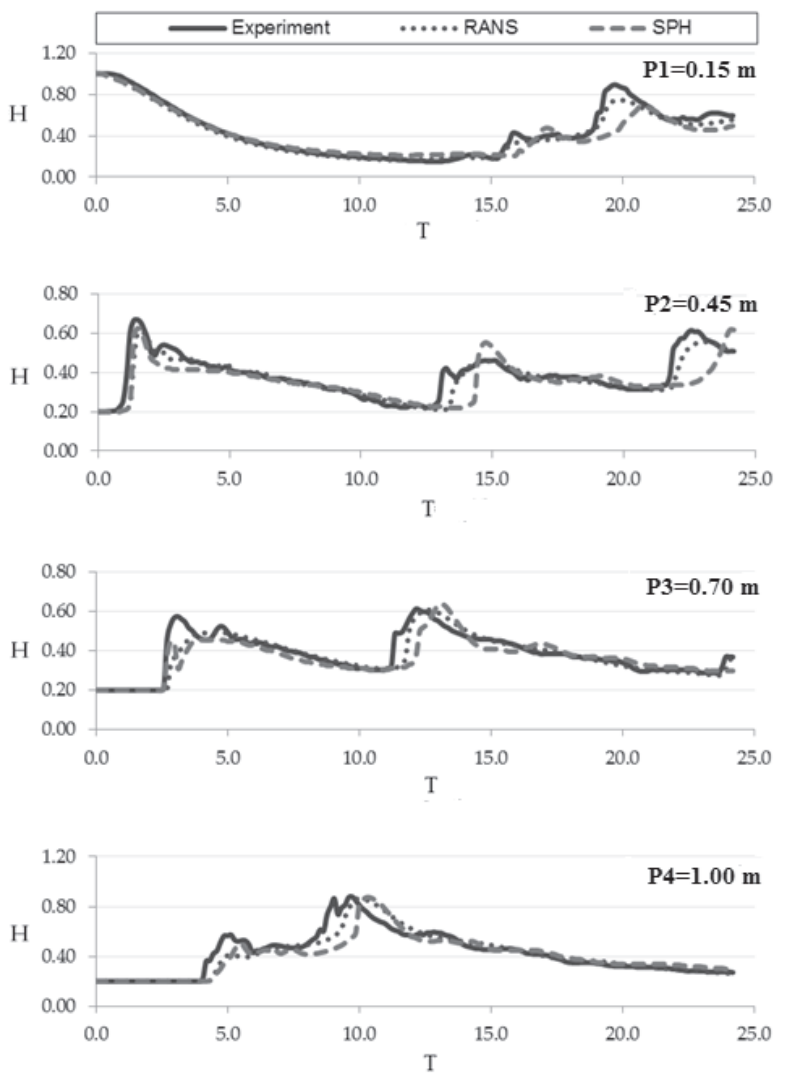

Fig. 11. Experimental and numerical comparison of flow depth variations with time for $\alpha=0.20$ at (P1, P2, P3, and P4). the case of $\alpha=0.20$ than that of $\alpha=0.10$. As also seen in previous studies, the intensity of turbulence and surface roughness play an important role on results [5, 10, 42].

As shown in Fig. 12, the resisting force of the tailwater significantly increases with depth ratio $(\alpha=0.40)$, and the result in the speed of the shock wave is slower than that in lower $\alpha$ cases. Thus, the wave front evidently sharpens between $t=0.1837 \mathrm{~s}$ and $\mathrm{t}=0.2839$ s. In Fig. 13 at $\mathrm{t}=1.002$, salt water starts to move in the upstream direction with the effect of the shock wave impact on the end wall.

Fig. 13 prominently denotes the methodological differences on the wave propagations of RANS mesh and SPH particle methods, particularly in terms of reservoir water and tailwater interaction. Fig. 14 shows the comparison of the experimental and numerical results of dimensionless time versus water depth at four locations for $\alpha=0.40$.

Fig. 14 indicates that $\alpha=0.40$ gives the best result of three $\alpha$ cases. There are quite good agreements between the numerical simulation results and experimental data [45]. However, both numerical results show slight discrepancies on the wave front and peak levels at $\mathrm{P} 1=0.15 \mathrm{~m}$. These discrepancies can result from parameter selections. In RANS, a grid size was adopted as $5 \mathrm{~mm}$ after performing sensitivity analysis for $2 \mathrm{~mm}$ and $10 \mathrm{~mm}$. In $\mathrm{SPH}$, several parameters were tested in order to perform sensitivity analysis, for example, different artificial viscosity values were tried between 0.05-0.20 and the optimum value was determined as 0.10 . Additionally, dp was taken as 0.001 and it was not tried smaller than 0.001 due to avoiding computational load. Smoothing length was defined as 1.0. At locations P2 and P3, the RANS approach reproduces depth versus time graphs, while the SPH method slightly 


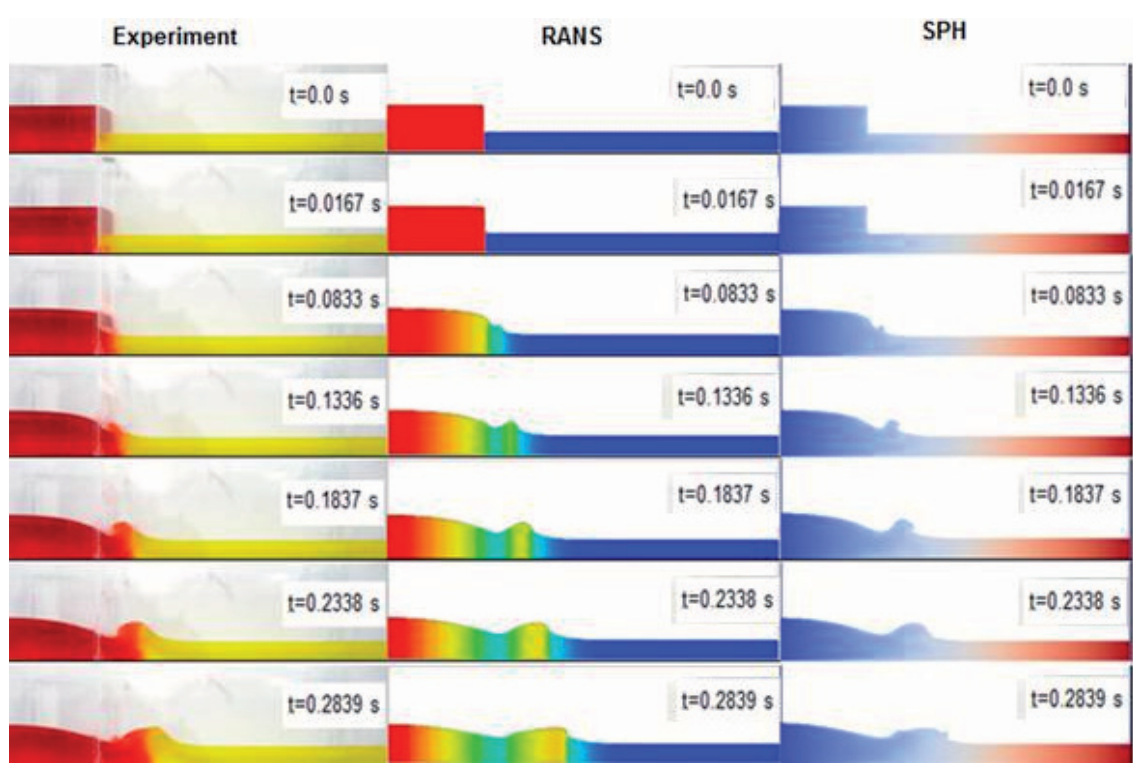

Fig. 12. Evolution of surface profiles with time at very early stages after gate lifting from $t=0.0$ to $t=0.2839 \mathrm{~s}$ for $\alpha=0.40$ (experiment, RANS, and SPH).

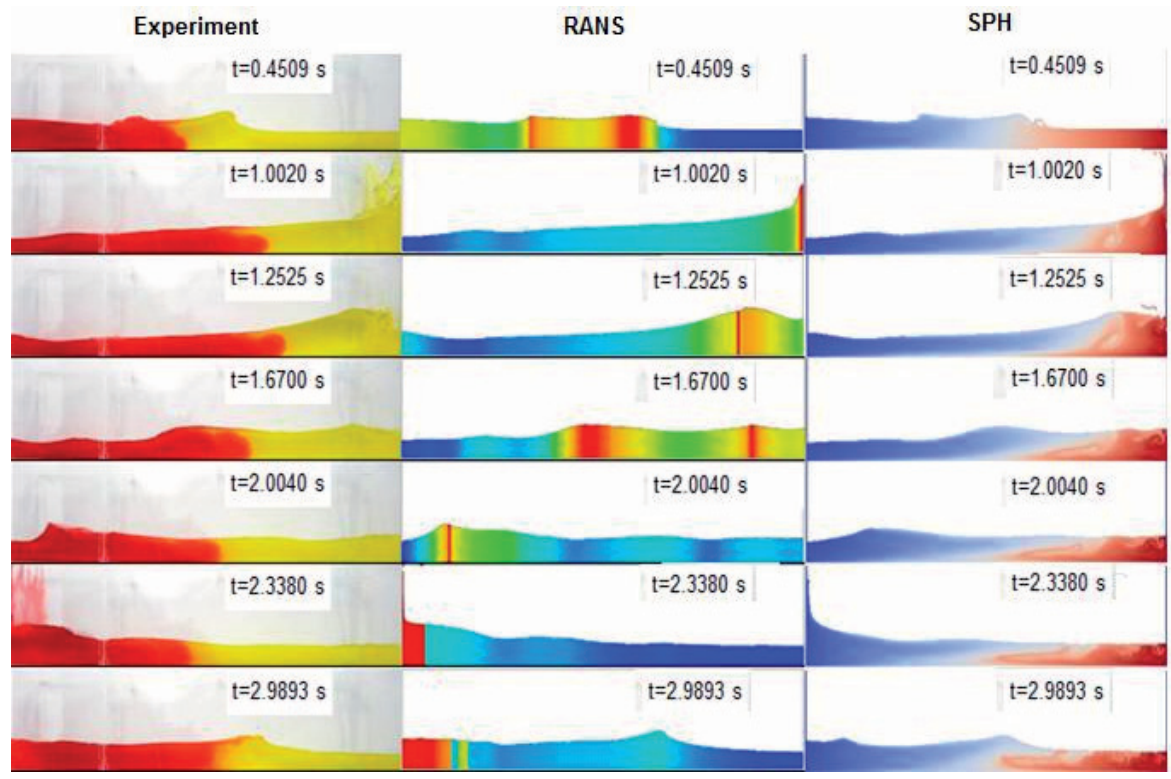

Fig. 13. Evolution of free surface profiles of reflected waves with time from $\mathrm{t}=0.4509 \mathrm{~s}$ to $\mathrm{t}=2.9893 \mathrm{~s}$ for $\alpha=0.40$ (experiment, RANS, and $\mathrm{SPH})$.

underestimates the flow depths around peak values. The best agreement of both numerical approaches with the experimental data is seen on the last graph, which designates the location $\mathrm{P} 4=1.00 \mathrm{~m}$.

\section{Conclusions}

The present study investigates the propagation of shock wave caused by sudden lifting of a vertical gate separating two different water levels at different heights, reservoir and downstream channel over initially wet channel with three distinct tailwater levels. New experimental data was obtained using digital image processing in a rectangular prismatic channel filled with salt water over a horizontal bed. Herein, using salt water can point out sea water where tsunamis occur, also covered by this topic. The adopted nonintrusive measuring technique yielded valuable results concerning time evolutions of both free surface profiles and flow depths through the entire channel without the necessity of any physical instrument within the channel. Therefore, the flow is undisturbed. Furthermore, the flow was numerically simulated with two distinct approaches: 

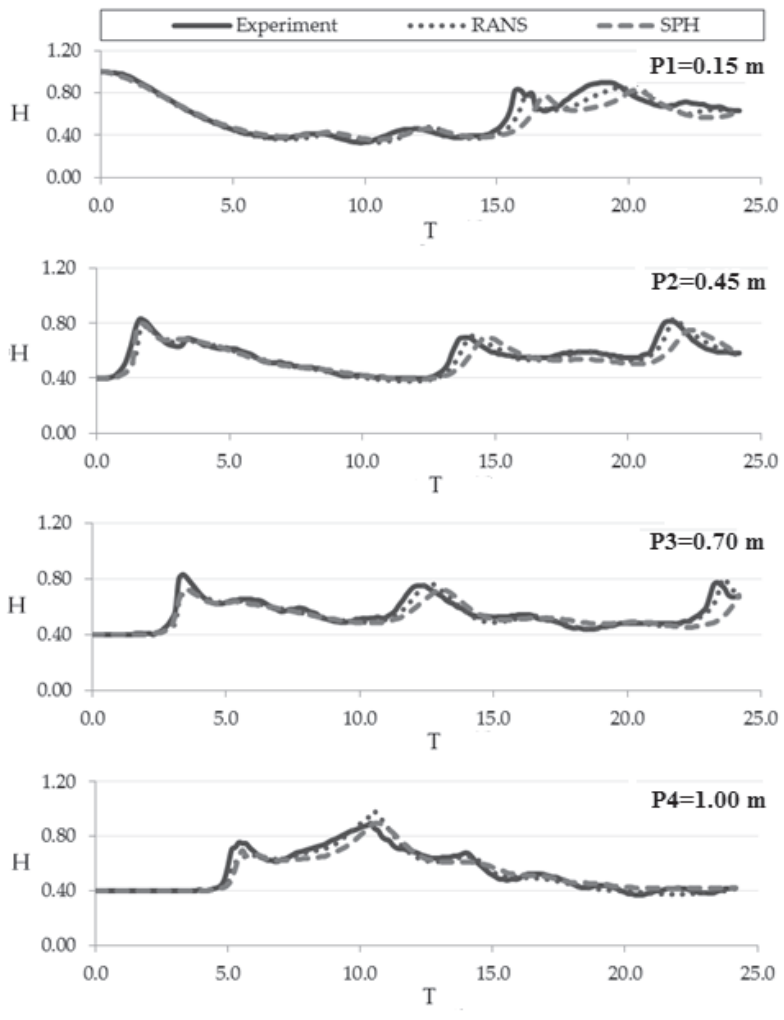

Fig. 14. Experimental and numerical comparison of flow depth variations with time for $\alpha=0.40$ at (P1, P2, P3, and P4).

VOF-based RANS by utilizing CFD package of flow-3D and SPH by DualSPHysics. By using salt water instead of water, the simulation ability of numerical methods for different density fluids was tested.

To understand the tailwater level effect on shockwave propagation, three different depth ratios of $0.10,0.20$, and 0.40 were considered. As depth ratio increases, the pressure and resisting forces along the downstream increase. As a result, moving salt water in the reservoir after sudden gate lifting is forced to move in a vertical direction. Therefore, free surface of the wave front sharpens over time and wave breaking is delayed. The most chaotic flow case in terms of turbulence intensity, air entrainment, and early wave breaking is observed in the shallow downstream salt water case of $\alpha=0.10$. Herein, both the speed of wave front and the kinetic energy are high compared with $\alpha=0.20$ and $\alpha=0.40$ cases. However, the speed of the reflected wave front in the upstream direction decreases and the flow depth rises while the depth ratio increases. As the initial tailwater levels increase, both numerical methods produce good results in the prediction of reflected wave front and average water levels. Namely, the best agreement between the numerical results and experimental data was provided in the deep downstream salt water case of $\alpha=0.40$. In general, RANS simulation yields better results than SPH simulation.

In future studies, SPH may be a good alternative method to CFD solvers in computation of rapidly varied unsteady flow problems. However, researchers should pay attention to accurate estimation of required parameters such as artificial viscosity and smoothing length by executing sensitivity analysis. Consequently, the current laboratory data can be useful in validating numerical solutions for the scientific community since there are limited experimental studies in the literature.

\section{Acknowledgements}

This study was supported by Cukurova University Research Fund Project No. FDK-2015-4887. The authors gratefully acknowledge this support.

\section{Conflicts of Interest}

The authors declare no conflict of interest.

\section{References}

1. STOKER J.J. Water waves. Interscience Publishers, Wiley, Newyork, 333, 1957.

2. BELLOS V., SOULIS J.V., SAKKAS J.G. Experimental investigation of two-dimensional dam-break induced flows. Journal of Hydraulic Research, 30, 47, 1992.

3. MOHAPATRA P.K., BHALLAMUDI S.M. Computation of a dam-break flood wave in channel transitions. Advances in Water Resources, 19, 181, 1996.

4. LAUBER G., HAGER W.H. Experiments to dam break wave: horizontal channel. Journal of Hydraulic Research, 36, 291, 1998.

5. STANSBY P.K., CHEGINI A., BARNES T.C.D. The initial stages of dam-break flow. J. Fluid Mech., 374, 407, 1998.

6. BUKREEV V.I., GUSEV A.B., MALYSHEVA A.A. Experimental verification of the gas-hydraulic analogy with reference to the dam-break problem. Fluid Dynamics, 39, 801, 2003.

7. JANOSI I.M., JAN D., SZABO K.G., TEL T. Turbulent drag reduction in dam-break flows. Experiments in Fluids, 37, 219, 2004.

8. CHANSON H., JARNY S., COUSSOT P. Dam break wave of thixotropic fluid. Journal of Hydraulic Engineering, ASCE, 132, 280, 2006.

9. KOCAMAN S. Experimental and theoretical investigation of dam-break problem. PhD Thesis. Çukurova University, Institute of Natural and Applied Sciences, Adana, 1, 2007.

10. KOCAMAN S., OZMEN-CAGATAY H. Investigation of dam-break induced shock waves impact on a vertical wall. Journal of Hydrology, 525, 1, 2015. doi.org/10.1016/j. jhydrol.2015.03.040

11. EVANGELISTA S. Experiments and numerical simulations of dike erosion due to a wave impact. Water, MDPI, ISSN 2073-4441, 7 (10), 5831, 2015. doi. org $/ 10.3390 /$ w7105831

12. AURELI F., DAZZI S., MARANZONI A., MIGNOSA P., VACONDIO R. Experimental and numerical evaluation of the force due to the impact of a dam-break wave on a structure. Advances in Water Resources, 76, 29-42, 2015. doi.org/10.1016/j.advwatres.2014.11.009 
13. DI CRISTO C., EVANGELISTA S., IERVOLINO M., GRECO M., LEOPARDI A., VACCA A. Dam-break waves over an erodible embankment: experiments and simulations. Journal of Hydraulic Research, 56, 196-210, 2017. doi.org/10.1080/00221686.2017.1313322

14. GOMEZ-GESTEIRA M., DALRYMPLE R.A. Using a three-dimensional smoothed particle hydrodynamics method for wave impact on a tall structure. Journal of Waterways, Ports, Coasts and Ocean Engineering, ASCE, 130, 63, 2004.

15. DALRYMPLE R.A., ROGERS B. Numerical modeling of water waves with the SPH method. Coastal Engineering, 53, 141, 2006.

16. CRESPO A.J.C. Application of the smoothed particle hydrodynamics model SPHysics to free - surface hydrodynamics. PhD Thesis. Universidade De Vigo, Departamento De Fisica Aplicada, 1, 2008.

17. SHAKIBAEINIA A., JIN Y.C. A mesh-free particle model for simulation of mobile-bed dam break. Advances in Water Resources, 34, 794-807, 2011. doi.org/10.1016/j. advwatres.2011.04.011

18. XU X. An improved SPH approach for simulating 3D dam-break flows with breaking waves. Computer Methods Applied Mechanics and Engineering, 311, 723, 2016.

19. JIAN W., LIANG D., SHAO S., CHEN R., YANG K. Smoothed Particle Hydrodynamics simulations of dambreak flows around movable structures. International Journal of Offshore and Polar Engineering, 26 (1), 1, 2016.

20. TURHAN E. The investigation of dam-break flow using with experimental and smoothing particle hydrodynamics methods. PhD Thesis. Çukurova University, Institute of Natural and Applied Sciences, Adana, 1, 2017.

21. ZHANG T., FANG F., FENG P. Simulation of dam/leevebreak hydrodynamics with a three-dimensional implicit unstructured-mesh finite element model. Environmental Fluid Mechanics, 17(5), 959-979, 2017. doi.org/10.1007/ s10652-017-9530-3

22. KOCAMAN S., OZMEN-CAGATAY H. The effect of lateral channel contraction on dam-break flows: Laboratory experiment. Journal of Hydrology, 432-433, 145, 2012.

23. CUBOS-RAMIREZ J.M., RAMIREZ-CRUZ J., SALINAS-VAZQUEZ M., VICENTE-RODRIGUEZ W., MARTINEZ-ESPINOSA E., LAGARZA-CORTES C. Efficient two-phase mass-conserving level set method for simulation of incompressible turbulent free surface flows with large density ratio. Computers and Fluids, 136, 212, 2016. doi.org/10.1016/j.compfluid.2016.05.032

24. EVANGELISTA S., ALTINAKAR M., DI CRISTO C. and LEOPARDI A. Simuation of dam-break waves on movable beds using a multi-stage centered scheme. International Journal of Sediment Research, ISSN: 1001-6279, 28 (3), 269, 2013.

25. SONG L., ZHOU J., LI Q., YANG X., ZHANG Y. An unstructured finite volume model for dam-break floods with wet/dry fronts over complex topography. International Journal of Numerical Methods in Fluids, 67, 960-980, 2011. doi.org/10.1002/fld.2397

26. BOUGUET J.Y. Camera calibration toolbox for Matlab. Computational Vision at the California Institute of Technology, 2004.

27. WILCOX D.C. Turbulence modelling for CFD. DCW Industries, Inc., La Canada CA, 2000.

28. KOCAMAN S., GUZEL H. Numerical and experimental investigation of dam-break wave on a single building situated downstream. Proceedings of International Balkans
Conference on Challenges of Civil Engineering, BCCE, EPOKA University, Tirana, Albania, 2011.

29. OZMEN-CAGATAY H., KOCAMAN S., GUZEL H. Investigation of dam-break flood waves in a dry channel with a hump. Journal of Hydro-Environment Research, 8, 304-315, 2014. doi.org/10.1016/j.jher.2014.01.005

30. FLOW SCIENCE INC. Flow-3D user manual. Santa FE NM, 2017.

31. VACONDIO R. Shallow water and Navier-Stokes SPH-like numerical modelling of rapidly varying free-surface flows. PhD Thesis. Universita degli Studi di Parma, Gennaio, 1, 2010.

32. OZBULUT M. Investigation of the violent free surface flows by using smoothed particle hydrodynamics. PhD Thesis. Istanbul Technical University, Grade School of Science Engineering and Technology, Istanbul, 1, 2013.

33. ALTOMARE C., CRESPO A.J.C., DOMINGUEZ J.M., GOMEZ-GESTEIRA M., SUZUKI T., VERWAEST T. Applicability of smoothed particle hydrodynamics for estimation of sea wave impact on coastal structures. Coastal Engineering, 96, 1, 2015.

34. MONAGHAN J.J., KOCHARYAN A. SPH simulation of multi-phase flow. Computer Physics Communications, 87, 225, 1994.

35. DOMINGUEZ J.M., CRESPO A.J.C., GOMEZGESTEIRA M. Optimization strategies for CPU and GPU implementaitons of a smoothed particle hydrodynamics method. Computer Physics Communications, 184, 617, 2012.

36. CUNNINGHAM L.S., ROGERS B.D., PRINGGANA G. Tsunami wave and structure interaction: an investigation with smoothed particle hydrodynamics. Engineering and Computational Mechanics, 167, 126, 2014.

37. GOMEZ-GESTEIRA M., ROGERS B.D., DALRYMPLE R.A., CRESPO A.J.C., NARAYANASWAMY M. User guide for the SPHysics code. 1, 2010.

38. DUALSPHYSICS TEAM. DualSPHysics user guide. User Guide For DualSPHysics Code, 1, 2016.

39. VACONDIO R., MIGNOSA P., PAGANI S. 3D SPH numerical simulation of the wave generated by the Vajont rockslide. Advances in Water Resources, 59, 146, 2013.

40. BARREIRO A., CRESPO A.J.C., DOMINGUEZ J.M., GOMEZ-GESTEIRA M. Smoothed particle hydrodynamics for coastal engineering problems. Computers and Structures, 120, 96, 2013.

41. GOMEZ-GESTEIRA M., ROGERS B.D., CRESPO A.J.C., DALRYMPLE R.A., NARAYANASWAMY M., DOMINGUEZ J.M. SPHysics - development of a free surface fluid solver-part 1: theory and formulations. Computer and Geosciences, 48, 289, 2012.

42. OZMEN-CAGATAY H., KOCAMAN S. Dam-break flows during initial stage using SWE and RANS approaches. Journal of Hydraulic Research, 48 (5), 603, 2010.

43. SHIGEMATSU T., LIU P.L.F., ODA K. Numerical modeling of the initial stages of dam-break waves. Journal of Hydraulic Research, 42, 183, 2004.

44. HE Z., WU T., WENG H., HU P., WU G. Numerical simulation of dam-break flow and bed change considering the vegetation effects. International Journal of Sediment Research, 32, 105-120, 2017. doi.org/10.1016/j. ijsrc.2015.04.004

45. YE Z., ZHAO X. Investigation of water-water interface in dam break flow with a wet bed. Journal of Hydrology, 548, 104-120, 2017. doi.org/10.1016/j.jhydrol.2017.02.055 